\title{
A low dose of an organophosphate insecticide causes dysbiosis and sex-dependent responses in the intestinal microbiota of the Japanese quail (Coturnix japonica)
}

Eduardo Crisol-Martínez, Laura T Moreno-Moyano, Ngare Wilkinson, Tanka Prasai, Philip H Brown, Robert J Moore, Dragana Stanley

Organophosphate insecticides have been directly or indirectly implicated in avian populations declining worldwide. Birds in agricultural environments are commonly exposed to these insecticides, mainly through ingestion of invertebrates after insecticide application. Despite insecticide exposure in birds occurring mostly by ingestion, the impact of organophosphates on the avian digestive system has been poorly researched. In this work we used the Japanese quail (Coturnix japonica) as an avian model to study short-term microbial community responses to a single dose of trichlorfon at low concentration in three sample origins of the gastrointestinal tract (GIT): cecum, large intestine and faeces. Using next-generation sequencing of 16S rRNA gene amplicons as bacterial markers, the study showed that ingestion of insecticide caused significant changes in the GIT microbiome. Specifically, microbiota composition and diversity differed between treated and untreated quail. Insecticide-associated responses in the cecum showed differences between sexes which did not occur with the other sample types. In cecal microbiota only treated females showed significant shifts in a number of genera within the Lachnospiraceae and the Enterobacteriaceae families. The major responses in the large intestine were a significant reduction in the genus Lactobacillus and increases in abundance of a number of Proteobacteria genera. All microbial shifts in faeces occurred in phylotypes that were represented at low proportional abundances. In general, changes in microbiota possibly resulted from contrasting responses towards the insecticide, either positive (e.g. biodegrading bacteria) or negative (e.g. insecticide-susceptible bacteria). This study demonstrates the significant impact that organosphate insecticides have on the avian gut microbiota; showing that a single small dose of trichlorfon caused dysbiosis in the GIT of the Japanese quail. Further research is necessary to understand the implications on birds' health, especially in females. 


\section{A low dose of an organophosphate insecticide causes}

\section{2 dysbiosis and sex-dependent responses in the intestinal}

3 microbiota of the Japanese quail (Coturnix japonica)

4 Eduardo Crisol-Martínez ${ }^{1}$, Laura T. Moreno-Moyano ${ }^{2}$, Ngare Wilkinson ${ }^{1,3,4}$, Tanka Prasai ${ }^{1,3}$,

5 Philip H. Brown ${ }^{1,3}$, Robert J. Moore ${ }^{4,5}$, Dragana Stanley ${ }^{1,3,4}$

$6{ }^{1}$ School of Medical and Applied Sciences, Central Queensland University, Rockhampton,

7 Queensland, Australia

$8{ }^{2}$ School of Biosciences, University of Melbourne, Parkville, Victoria, Australia

$9{ }^{3}$ Institute of Future Farming, Central Queensland University, Rockhampton, Queensland,

10 Australia

$11{ }^{4}$ Poultry Cooperative Research Centre, University of New England, Armidale, New South

12 Wales, Australia

$13{ }^{5}$ School of Science, RMIT University, Bundoora, Victoria, Australia

14 Corresponding author:

15 Eduardo Crisol-Martínez ${ }^{1}$

16 Current address: Central Queensland University, 120 Spencer Street, Melbourne, Victoria, 3000,

17 Australia

18 Email: eduardocrisol@gmail.com 


\section{Abstract}

25

26

Organophosphate insecticides have been directly or indirectly implicated in avian populations declining worldwide. Birds in agricultural environments are commonly exposed to these insecticides, mainly through ingestion of invertebrates after insecticide application. Despite insecticide exposure in birds occurring mostly by ingestion, the impact of organophosphates on the avian digestive system has been poorly researched. In this work we used the Japanese quail (Coturnix japonica) as an avian model to study short-term microbial community responses to a single dose of trichlorfon at low concentration in three sample origins of the gastrointestinal tract (GIT): caecum, large intestine and faeces. Using next-generation sequencing of 16S rRNA gene amplicons as bacterial markers, the study showed that ingestion of insecticide caused significant changes in the GIT microbiome. Specifically, microbiota composition and diversity differed between treated and untreated quail. Insecticide-associated responses in the caecum showed differences between sexes which did not occur with the other sample types. In caecal microbiota only treated females showed significant shifts in a number of genera within the Lachnospiraceae and the Enterobacteriaceae families. The major responses in the large intestine were a significant reduction in the genus Lactobacillus and increases in abundance of a number of Proteobacteria genera. All microbial shifts in faeces occurred in phylotypes that were represented at low relative abundances. In general, changes in microbiota possibly resulted from contrasting responses towards the insecticide, either positive (e.g. biodegrading bacteria) or negative (e.g. insecticidesusceptible bacteria). This study demonstrates the significant impact that organophosphate insecticides have on the avian gut microbiota; showing that a single small dose of trichlorfon caused dysbiosis in the GIT of the Japanese quail. Further research is necessary to understand the implications on birds' health, especially in females.

\section{Introduction}

Organophosphates are the most widely applied insecticides (Bondarenko et al. 2004; Zamy et al. 2004), and they primarily act by inhibiting cholinesterase, a nervous system enzyme (Marrs 1993). Avian exposure to these contaminants occurs through dermal contact, maternal transfer, inhalation and ingestion (Smith et al. 2007). Among all of these routes, ingestion is the predominant pathway of avian exposure, which can occur through the consumption of prey items 
53 such as insects that have been previously exposed and/or killed by insecticides (Golden \&

54 Rattner 2003). Several studies have reported how organophosphate insecticides caused the mass

55

56

57

58

59

60

61

62

63

64

65

66

67 death of birds (e.g. Fleischli et al. 2004; Frank et al. 1991), some of these through ingestion of contaminated prey (e.g. Goldstein et al. 1999; Goldstein et al. 1996). While these lethal responses to insecticide ingestion highlight toxicity to birds, few studies have examined effects of ingestion of sub-lethal organophosphate dosage on the gastrointestinal tract which may lead to chronic effects on bird health.

Trichlorfon is an organophosphate insecticide, which has been used since the 1950s in a wide number of systems, including tree orchards, vines, fruits, vegetables, field crops, pastures, forests, and turf (de Oliveira et al. 2002). Trichlorfon is considered moderately toxic to birds (e.g. LC50 values in bobwhite quail [Colinus virginianus] $=720 \mathrm{ppm}$; in Japanese quail [Coturnix japonica $]=1901$ ppm) (Hill et al. 1975). Most of the toxicological research on trichlorfon in avian species has focused on its neurotoxicity; generally shown as severe decreases in anticholinesterase activity (e.g. Hill 1982; Iko et al. 2003). The majority of the toxicological assessments have used relatively high insecticide concentrations derived from general measures of toxicity such as the lethal dose or lethal concentration values of the species tested (e.g. de Oliveira et al. 2002; Slott \& Ecobichon 1984). However, little work has assessed the toxicological impacts of insecticides using insecticide concentrations representative of likely exposure levels in the field; such as residues present at a given time after their application (e.g. Joly et al. 2013). Residue levels in pesticide-exposed items can be measured to calculate how much of the contaminant is ingested by birds to then understand the context of impact assessment (Smith et al. 2007).

Although the digestive system is the first contact point for contaminants, few studies have aimed to understand the toxicological impacts of pesticides on the gastrointestinal tract (GIT) (Joly et al. 2013). The microbiota present throughout the GIT is essential in development and maturation of the immune system (Kelly \& Conway 2005; Umesaki et al. 1999). The GIT microbiota contributes to digestive and fermentative processes, and prevents colonization by pathogens (Kamada et al. 2013), ultimately contributing to the energy and nutrient supply, immunity, and general well-being of the host (Stanley et al. 2014). The importance that host-microbiome symbiotic relationships have in the success of animals is only recently being recognized by 
83 evolutionary biologists and ecologists (McFall-Ngai et al. 2013). However, environmental 84 stresses can shift these relationships, thus affecting host performance and/or health (Myers 85 2004).

86 To date, most of the studies characterising the GIT microbiota of birds have been carried out in 87 chickens (e.g. Dumonceaux et al. 2006; Stanley et al. 2013). Only a few other studies have 88 characterised the microbiota of other bird species, including kakapo (Strigops habroptilus), emu 89 (Dromaius novaehollandiae), turkey (Meleagris spp.) (Waite \& Taylor 2014), bobwhite quail 90 (Su et al. 2014), and Japanese quail (Wilkinson et al. 2016). The avian GIT is shorter than that of mammals, thus decreasing food transit time (Golian \& Maurice 1992), and it is colonized by a unique microbiome adapted to the host (Stanley et al. 2014). Previous research has assessed the impact of chronic low-dose organophosphate insecticide exposure on the GIT microflora of rats and a human GIT simulator (Joly et al. 2013). However, to our knowledge, none has studied the impact of organophosphate insecticides on GIT microbiota of any avian species.

In this study, trichlorfon was selected as a representative organophosphate insecticide, and the Japanese quail was chosen as an indicative avian model, as suggested elsewhere (Foudoulakis et al. 2013). The general aim of this study was to understand the immediate toxicological effects that trichlorfon residues may produce on the intestinal microbiota of the Japanese quail. Specifically, our aims were to: i) assess the potential impacts that a single oral dose of a low concentration of trichlorfon (equivalent to that present in a bird when feeding upon arthropods in an orchard 48 hours after spraying at the minimum commercially recommended dose) had on the microbial GIT of the Japanese quail after 24 hours of exposure. The impact of trichlorfon were assessed by means of shifts in the microbial community composition of the caecum, large intestine and faeces, and ii) compare these shifts between sexes.

\section{Materials and methods}

\section{Experimental birds}

Fertilized eggs were obtained from Banyard Game Birds farm, Toowoomba, Queensland. The line of quail has been bred for over 20 years without the use of antibiotics and growth promoters.

110 The Banyard Game Birds practice natural hatchery operations without fumigation or sterilization 111 of the eggs, thus ensuring essential transfer of maternal microbiota to the next generation 
112 (Stanley et al. 2013). Hatchlings were housed together in a rearing pen until they reached three

113 weeks of age, when they were separated to male and female to avoid male fighting over the 114 females, and allocated into a number of cages, each containing four birds, until the start of the 115 experiment at eight weeks of age. The bird stock at the time of the trial was three times higher 116 than the number used in this experiment allowing us to select the birds with near identical initial 117 weights taking each of the birds allocated to the same treatment from the different cage thus 118 avoiding the cage effects on microbiota. At the start of the experiment birds from the rearing 119 pens were transferred to individual cages and allocated to treatment groups. Throughout the rearing and experimental period the birds were housed in a temperature controlled room at $25{ }^{\circ} \mathrm{C}$,

121

122

123

124

125

126

127

128

129

130

131

132

133

134

135

136

137

138

139

140

141

natural light, feed and water was supplied ad libitum. Feed supplied to the birds from hatch was a commercial turkey starter (Ridley, Barastoc) (22\% protein, $2.5 \%$ fat, $5 \%$ fibre, with added $0.3 \%$ salt, $1 \%$ calcium, $8 \mathrm{mg} / \mathrm{kg}$ copper and $0.3 \mathrm{mg} / \mathrm{kg}$ selenium). The starter feed was replaced with Barastoc turkey grower feed (20\% protein, $2 \%$ fat, $6 \%$ fibre, $0.3 \%$ salt, $0.95 \%$ calcium, $8 \mathrm{mg} / \mathrm{kg}$ copper and $0.3 \mathrm{mg} / \mathrm{kg}$ selenium) at 4 weeks of age.

\section{Experimental design}

Twenty healthy adult quails of eight weeks-old (10 male and 10 female) were used for this experiment, (average weights; male $=300 \mathrm{~g}$ and female $=313.25 \mathrm{~g}$ ). At the beginning of the experiment, no significant differences in weight were found between treated and untreated quails by sex. Five birds of each sex were assigned to each of two treatments, insecticide-treated and untreated (control). Each of these 20 selected birds were then caged individually throughout the duration of the experiment. Japanese quails are early maturing, short lived birds with the lifespan of up to three years (Woodard \& Abplanalp 1971). By six weeks of age all females were laying eggs and all birds, both male and female were fully mature and considered adult.

Trichlorfon residue was estimated using a model specifically designed to calculate pesticide residues on avian food items (i.e. T-REX model, developed by the US Environmental Protection Agency [USEPA] [Sullivan \& Wisk 2013]). The T-REX model estimated that 48 hours after a single application of Lepidex 500 (containing $500 \mathrm{~g} / 1$ trichlorfon) at the lowest commercially recommended dose in tree crops (i.e. $100 \mathrm{ml} / 100$ 1), the concentration of trichlorfon residues present on arthropods was $26.42 \mathrm{ppm}$. Following the toxicity test protocol of the USEPA, the latter concentration was individually adjusted to each bird based on its estimated daily food 
142 intake (average $133 \mathrm{~g} /$ day) and its bodyweight (average $306.6 \mathrm{~g}$ ) (USEPA 1993). Final

143 trichlorfon concentrations (average $12 \mu \mathrm{g}$ trichlorfon/g bird weight) were calculated by

144 multiplying the estimated concentration of the trichlorfon residues present on arthropods by the

145 estimated daily food intake of each bird in $\mathrm{mg}$. These final trichlorfon concentrations were

146 adjusted to a final volume of $1 \mathrm{ml}$ using distilled water, and given to birds in the 'treated' group

147 by oral gavage in a single dose. Equal volumes of water were given by gavage to the birds in the

148 'untreated' group. Quails were continuously observed during the course of the experiment using

149 video cameras to monitor their behaviour. None of the birds died or showed abnormal behaviour.

150 Since the aim of the study was to characterize short-term GIT toxicological responses, birds were

151 euthanized 24 hours after the administration of trichlorfon by intramuscular overdose of

152 phenobarbitone sodium IP.

153 Samples from 3 origins (caecum, large intestine and faeces) were obtained from each quail.

154 Luminal specimens were obtained from caecum and large intestine by removing the contents and

155 placing into sterile containers. Faecal samples from each bird were collected within one hour

156 prior to necropsy. All samples were stored at $-80^{\circ} \mathrm{C}$ for a maximum of one week until DNA was

157 extracted.

158 Animal ethics statement

159 Animal ethics approval for the present project was obtained from the Animal Ethics Committees 160 of the Central Queensland University (permission number A14/03-309).

\section{Bioinformatics analysis}

162 Total DNA was isolated using the Bioline ISOLATE Faecal DNA Kit (\#BIO-52038) according 163 to the manufacturer's protocols. DNA was amplified across the V3-V4 16S rRNA gene region 164 using Q5 DNA polymerase (New England Biolabs). PCR conditions were; $98^{\circ} \mathrm{C}$ for 60 seconds 165 followed by 30 cycles of $98^{\circ} \mathrm{C}$ for 10 seconds, $49^{\circ} \mathrm{C}$ for 30 seconds, $72^{\circ} \mathrm{C}$ for 30 seconds, 166 followed by a final elongation at $72^{\circ} \mathrm{C}$ for $10 \mathrm{~min}$. Sequencing was performed on an Illumina 167 MiSeq ( 2 x 300 bp), based on the method detailed by Fadrosh et al. (2014). The quality filtered 168 sequences were analysed in QIIME 1.8 software (Caporaso et al. 2010). Sequences were joined 169 in QIIME using the fastq-join method with zero percent error allowed across the overlapping 170 region. Sequences were demultiplexed retaining only sequences with Phred quality score higher 
171 than 20. OTUs were picked using the Uclust algorithm (Edgar 2010) with 97\% sequence

172 similarity threshold and inspected for chimeric sequences using Pintail (Ashelford et al. 2005).

173 The OTU table was filtered to remove nonbacterial OTUs and OTUs that were of less than

$1740.01 \%$ abundance. Samples with less than 2000 sequences were removed from the analysis

175 resulting in 51 samples with high quality joined sequences, 25 from control and 26 samples from

176 insecticide treated groups. The filtered table was normalised using QIIME's default cumulative

177 sum scaling (CSS) method (Paulson et al. 2013). Additional taxonomic assignment was

178 performed using blastn (Altschul et al. 1997) against the NCBI 16S Microbial database. The

179 complete dataset is available on MG-RAST database (http://metagenomics.anl.gov/) under

180 project ID 4693672.3 .

181 Statistical analysis

182 Permutational analysis of variance (PERMANOVA) (Anderson 2005) was used to test for

183 differences in microbiota composition at the OTU level. Specifically, three fixed factors were

184 tested: Treatment (treated and untreated quails), Sex (male, female), and Origin (caecum, large

185 intestine, and faeces). Normalised data was used to calculate matrices using Bray-Curtis

186 distances. Data was permuted 9999 times (Anderson \& Braak 2003). Canonical Analysis of

187 Principal Coordinates (CAP) was used to visualize these differences in composition. Analysis of

188 Variance (ANOVA) tests were used to test for differences in community diversity, based on

189 Shannon diversity index values at the OTU level. ANOVA was also used to calculate significant

190 differences at higher microbiota taxonomic levels across factors. Additionally, a heat map was

191 created to depict positive and negative correlations between taxa based on Pearson's correlation

192 values. PERMANOVA and CAP were performed with PRIMER software (v.6.0) and

193 PERMANOVA+ software (v.1.0.6). Analyses of community diversity, taxonomic structure, and

194 heat maps were performed in Calypso (v.3.0) (http://bioinfo.qimr.edu.au/calypso/).

195 Results

196 Microbiota composition

197 Microbiota composition was significantly affected by Treatment (Pseudo-F=3.544, $\mathrm{P}=0.006$ ) and

198 Origin (Pseudo-F=11.267, $\mathrm{P} \leq 0.001$ ), but not by Sex (Pseudo-F=1.517, $\mathrm{P}=0.134$ ) (Fig. 1). There

199 was a significant Treatment $\times$ Origin interaction (Pseudo-F=2.748, $\mathrm{P}=0.004)$. There were highly 
200 significant differences in microbiota composition between treated and untreated quails in caecum 201 ( $\mathrm{t}=1.652, \mathrm{P}=0.001)$, faeces $(\mathrm{t}=1.759, \mathrm{P}=0.001)$, and large intestine, although the level of 202 significance of the latter was lower than the other two origins $(\mathrm{t}=1.512, \mathrm{P}=0.036)$. For untreated 203 quails, caecal microbiota differed significantly from those of faeces $(\mathrm{t}=2.883, \mathrm{P} \leq 0.001)$ and large 204 intestine $(\mathrm{t}=3.406, \mathrm{P} \leq 0.001)$. However the large intestine did not significantly differ in 205 microbiota composition from that of faeces ( $\mathrm{t}=1.158, \mathrm{P}=0.178)$ (Fig. 1). In treated birds, 206 differences in microbiota composition between each of the three origins were significant 207 (caecum, $\mathrm{t}=4.037, \mathrm{P} \leq 0.001$; large intestine, $\mathrm{t}=2.327, \mathrm{P} \leq 0.001$; faeces, $\mathrm{t}=2.030, \mathrm{P} \leq 0.001$ ) (Fig. 1). 208 209 


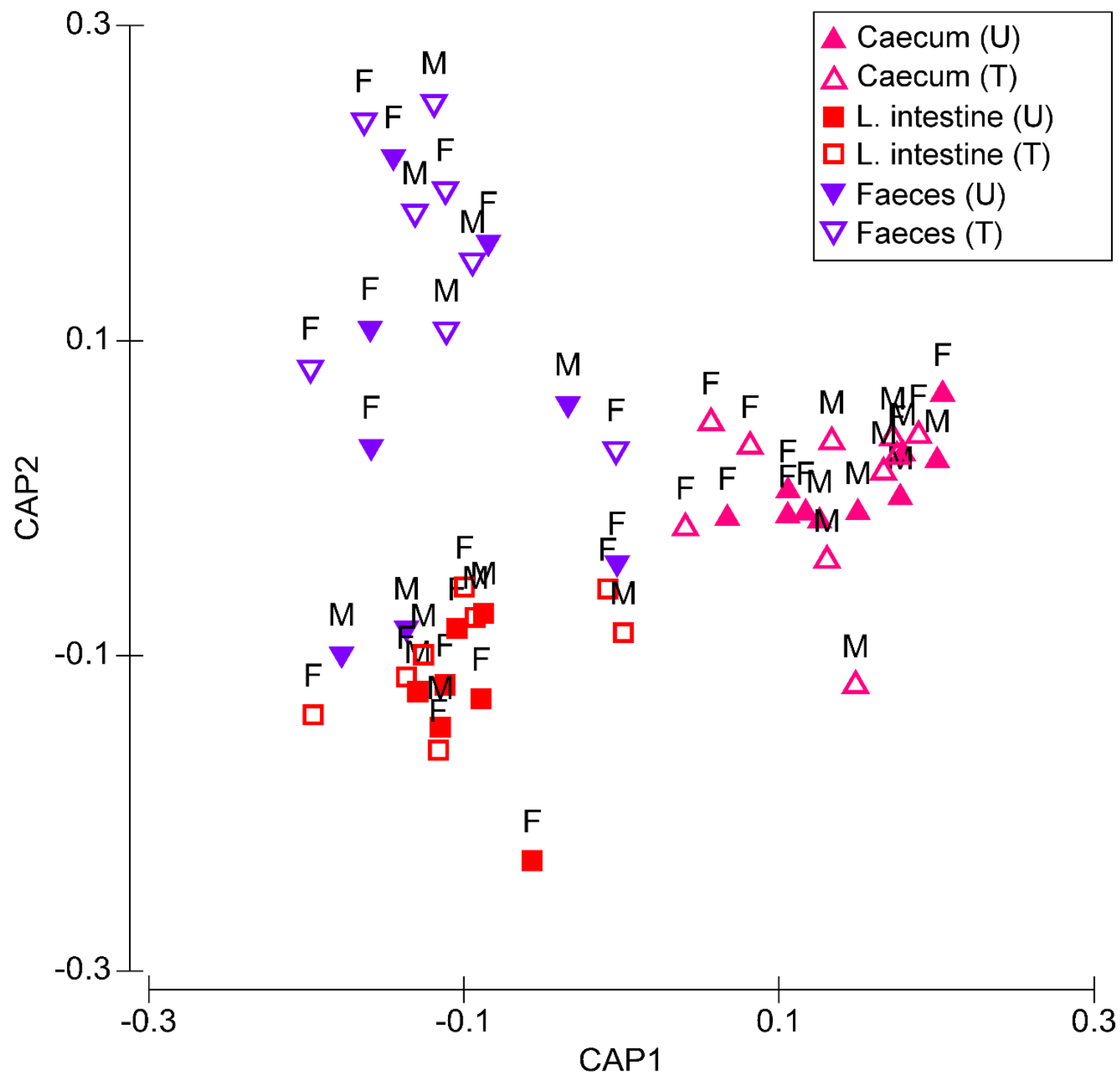

Fig. 1 Canonical analysis of principal coordinates (CAP) biplot showing a constrained by origin, nondimensional ordination of microbial community across all factors. Letter $\mathrm{U}$ in the sample legend indicates untreated control while $\mathrm{T}$ indicates insecticide-treated birds. $\mathrm{M}$ stands for male and $\mathrm{F}$ for female birds.

Differences between sexes were recorded in the response of microbiota to insecticide.

Particularly in the caecum, Treatment and Sex had a significant impact on the microbiota composition (respectively, Pseudo-F=2.728, $\mathrm{P}=0.002$ and Pseudo-F=2.139, $\mathrm{P}=0.023$ ). Pair-wise tests showed that treated females had a significantly different microbiota composition compared to non-treated females ( $\mathrm{t}=1.615, \mathrm{P}=0.036)$, while in males, these differences were not significant $(\mathrm{t}=1.212, \mathrm{P}=0.122)$ (Fig. 1). Treatment was the only significant source of variation in both the large intestine (Pseudo-F=2.285, $\mathrm{P}=0.027$ ) and faeces (Pseudo-F=3.093, $\mathrm{P}=0.002$ ) (Fig. 1). 
221 However, in the latter origin, pair-wise tests showed that Treatment had a significant effect on

222 the microbiota composition of males (Pseudo-F=1.607, $\mathrm{P}=0.028)$, but not on that of females

223 (Pseudo-F=1.224, $\mathrm{P}=0.085$ ).

\section{Microbiota diversity}

225 Community diversity differed significantly across each of the three factors $(\mathrm{P} \leq 0.001)$ (Fig. 2).

226 Overall, the average caecal microbiota diversity, at an OTU level, was higher than the other two

227 origins. Microbiota diversity in the caecum differed significantly between treated and untreated

228 females $(\mathrm{P}=0.019)$, but no significant differences were shown for the male microbiotas $(\mathrm{P}=0.185)$

229 (Fig. 2). Diversity in the large intestine did not differ significantly across Treatment or Sex (Fig.

230 2). In faeces, significant differences were found between treated and untreated males $(\mathrm{P}=0.003)$,

231 but not for the females ( $\mathrm{P}=0.605)$ (Fig. 2).

232

233

234

235

236

237

238

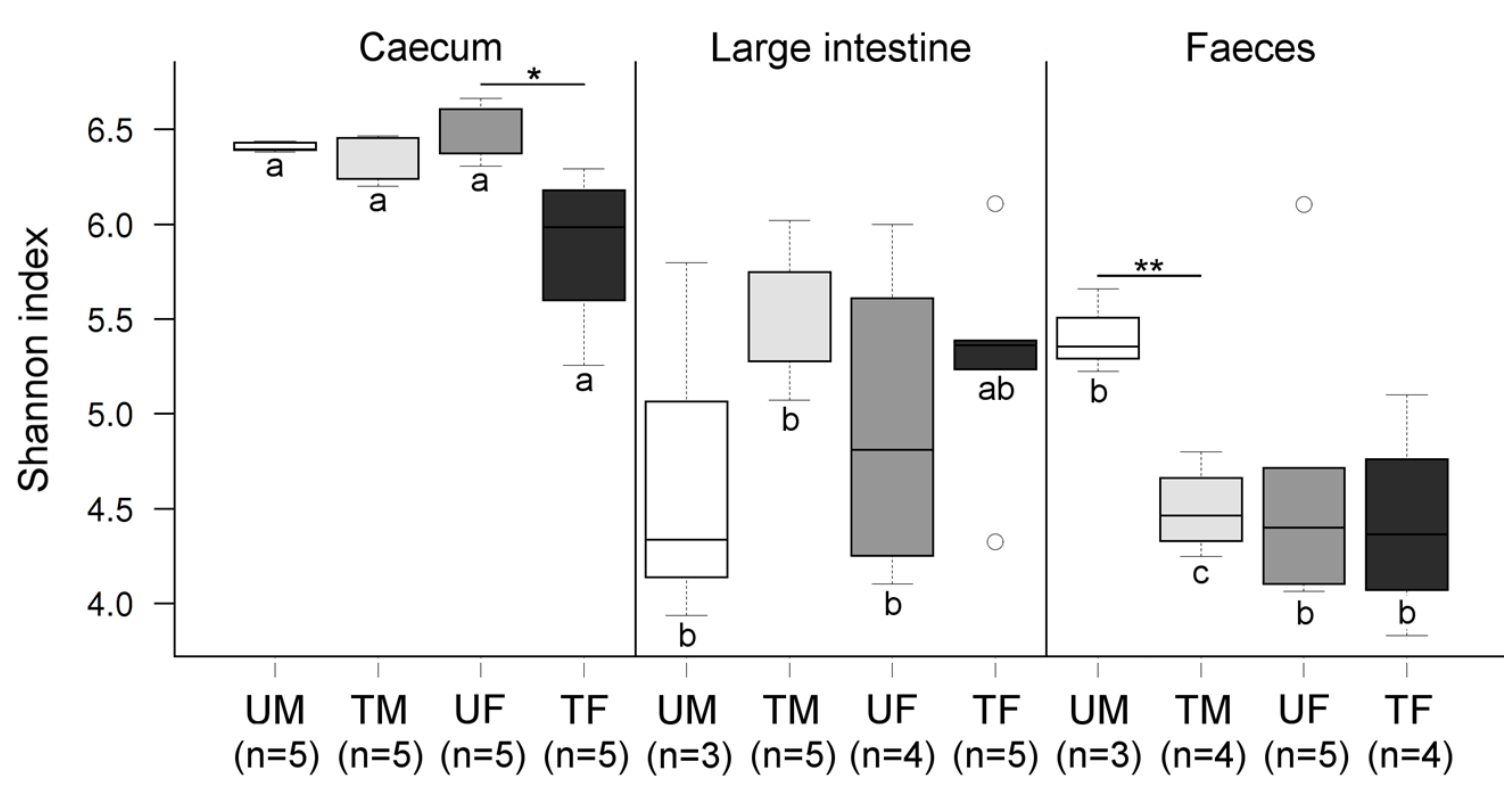

Fig. 2 Boxplots showing Shannon index values at the OTU level across factors. Within each origin, significant differences are indicated ('*' $\mathrm{P}<0.05$, ‘**' $\mathrm{P} \leq 0.01$ ). Same colours indicate groups of quails of the same sex and under the same treatment. Different letters indicate significant differences between these groups across origins. Letter $\mathrm{U}$ in the sample legend indicates untreated control while $\mathrm{T}$ indicates insecticide-treated birds. $\mathrm{M}$ stands for male and $\mathrm{F}$ for female birds. Number of samples are indicated.

\section{Caecum}


239 Overall, the caecum microbiota was represented by 9 phyla, 27 orders, 56 families, 87 genera, 240 and 1138 OTUs, based on 97\% sequence similarity and using the Uclust algorithm. Across

241 factors, the main three phyla ordered by relative abundance levels were Firmicutes (constituting 242 approximately $81 \%$ of abundance across groups), Bacteroidetes (10\%), and Proteobacteria (8\%).

243 The main genera represented in the caecal microbiota were Ruminococcus (15\%), Bacteroides 244 (10\%), Faecalibacterium (8\%), Clostridium (6\%), and Eubacterium (4\%).

245 Comparisons of the microbiota at the phylum level showed that in treated quails the abundance 246 of Proteobacteria was significantly increased ( $\mathrm{P}=0.007)$ (Fig. 3A). This occurred due to changes 247 at the family level, by similar significant relative increases in abundance of Enterobacteriaceae

248 (5.4 to $9.7 \%, \mathrm{P}=0.009$ ). Four genera contained in this family increased significantly in abundance 249 within the treated females, Klebsiella $(\mathrm{P}=0.016)$, Salmonella $(\mathrm{P}=0.032)$, Erwinia $(\mathrm{P}=0.016)$, and 250 Serratia $(\mathrm{P}=0.021)$ (Fig. 3A). Nevertheless, each of the latter three genera represented relative 251 abundances below 1\%. Significant increases also occurred in the phylum Bacteroidetes

$252(\mathrm{P}=0.043)$, linked to equally significant increases in the genus Bacteroides (Fig. 3B). The relative 253 abundance of the phylum Firmicutes decreased significantly from $84 \%$ in untreated to $77 \%$ in 254 treated quails $(\mathrm{P}=0.005)$. These results were related to a significant decrease of the family 255 Lachnospiraceae ( 55 to $47 \%, \mathrm{P}=0.023$ ). Three genera present in this family significantly 256 decreased in treated females, Eubacterium $(\mathrm{P}=0.008)$, Blautia $(\mathrm{P}=0.032)$, and Roseburia $257(\mathrm{P}=0.025)$ (Fig. 3C). When combining male and female quails, Coprococcus, an additional genus 258 from the same family, decreased significantly $(\mathrm{P}=0.035)$ (Fig. 3C). No significant differences 259 were found at the genus level in males. The heat map showed how each of the genera increasing 260 significantly in female quails were positively correlated between each other and negatively 261 correlated with four other genera: Coprococcus, Faecalibacterium, Ruminococcus, and Blautia 262 (Fig. 3D). 


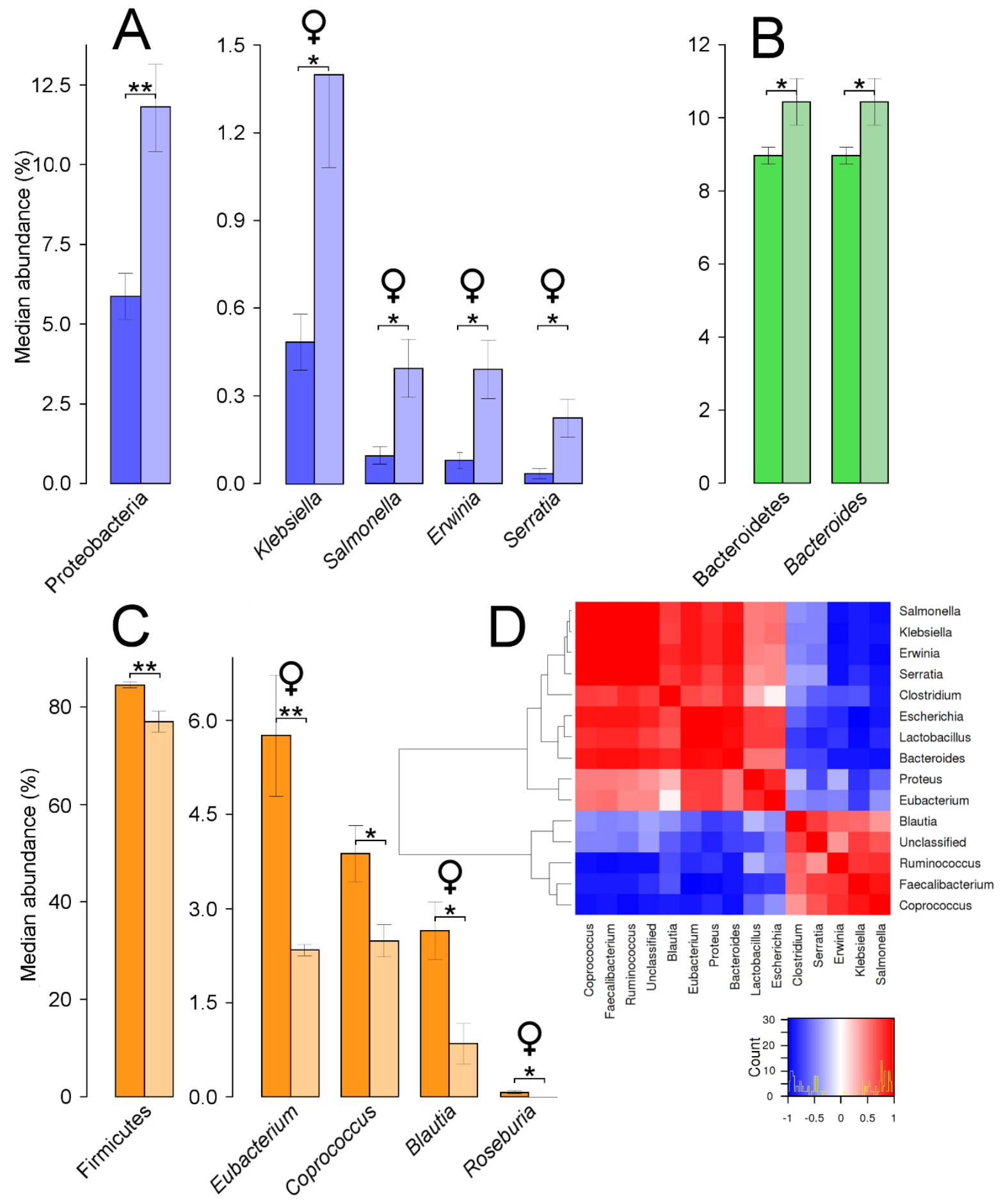

264 Fig. 3. Caecal microbial taxa showing significant shifts. These taxa were grouped in the phyla Proteobacteria (A),

265 Bacteroidetes (B), and Firmicutes (C); '*' indicates $\mathrm{P} \leq 0.05$, and ' $* *$ ' $\mathrm{P} \leq 0.01$. Light colours indicate treated birds.

266 Sex-dependent significant shifts are indicated with symbols. To facilitate comparisons across origins, taxa in the

267 same phylum is indicated by same colours in figures 3, 4, and 5. Panel D shows correlations between genera in 
268 treated females (at levels of abundance $>0.4 \%$ ), based on Pearson's correlation. A histogram indicates the

269 distribution of counts based on the correlation values.

\section{Large intestine}

271 The overall composition of the large intestine microbiota was represented by a total of 10 phyla,

27233 orders, 71 families, 103 genera, and 1068 OTUs. Based on averaged values across all factors,

273 the main phyla were Firmicutes (65\%), Proteobacteria (21\%), Bacteroidetes (7\%), and

274 Actinobacteria (5\%). The five most abundant genera were Lactobacillus (25\%), Ruminococcus

275 (6\%), Bacteroides (6\%), Clostridium (4\%), and Faecalibacterium (3\%).

276 Based on ANOVA rank tests, there were significant differences at the phylum level, as the

277 abundance of Firmicutes decreased from $76 \%$ in untreated to $55 \%$ in treated quails $(\mathrm{P}=0.014)$

278 (Fig. 4A). These changes were linked to significant decreases at the genus level in Lactobacillus

279 ( $\mathrm{P}=0.029)$ (Fig. 4A). The most abundant species under this genus was L. agilis, which was

280 assigned, using blast against 16S Microbial database, to a total of 36 OTUs as 'first choice'

281 identity (average $=93.3 \%, \min =86 \%, \max =98 \%$ ). This species' abundance dropped significantly

282 from $25 \%$ in untreated to $5 \%$ in treated quails $(\mathrm{P}=0.014)$ (Fig. 4A). The phylum

283 Verrucomicrobia, with a relative abundance of less than 1\%, significantly increased in treated

284 quails $(\mathrm{P}=0.038)$, due to equally significant increases in the genus Akkermansia (Fig. 4B).

285 Although not-significant, the Proteobacteria phylum increased from $15 \%$ in untreated to $27 \%$ in

286 treated quails, partly due to significant increases at the genus level in Klebsiella $(\mathrm{P}=0.019)$, and

287 at lower proportions (i.e. $<1 \%)$ in Rhodospirillum $(\mathrm{P}=0.045)$, Alkanindiges $(\mathrm{P}=0.019)$ and

288 Lysobacter $(\mathrm{P}=0.045)$. Also, significant increases in the genus $\operatorname{Agrobacterium}(\mathrm{P}=0.044)$

289 (comprised of an OTU 100\% identical to Agrobacterium fabrum) were found only in females

290 (Fig. 4C). Lastly, the proportion of unclassified genera increased significantly in treated quails

$291 \quad(\mathrm{P}=0.029)$ (Fig. 4D). 

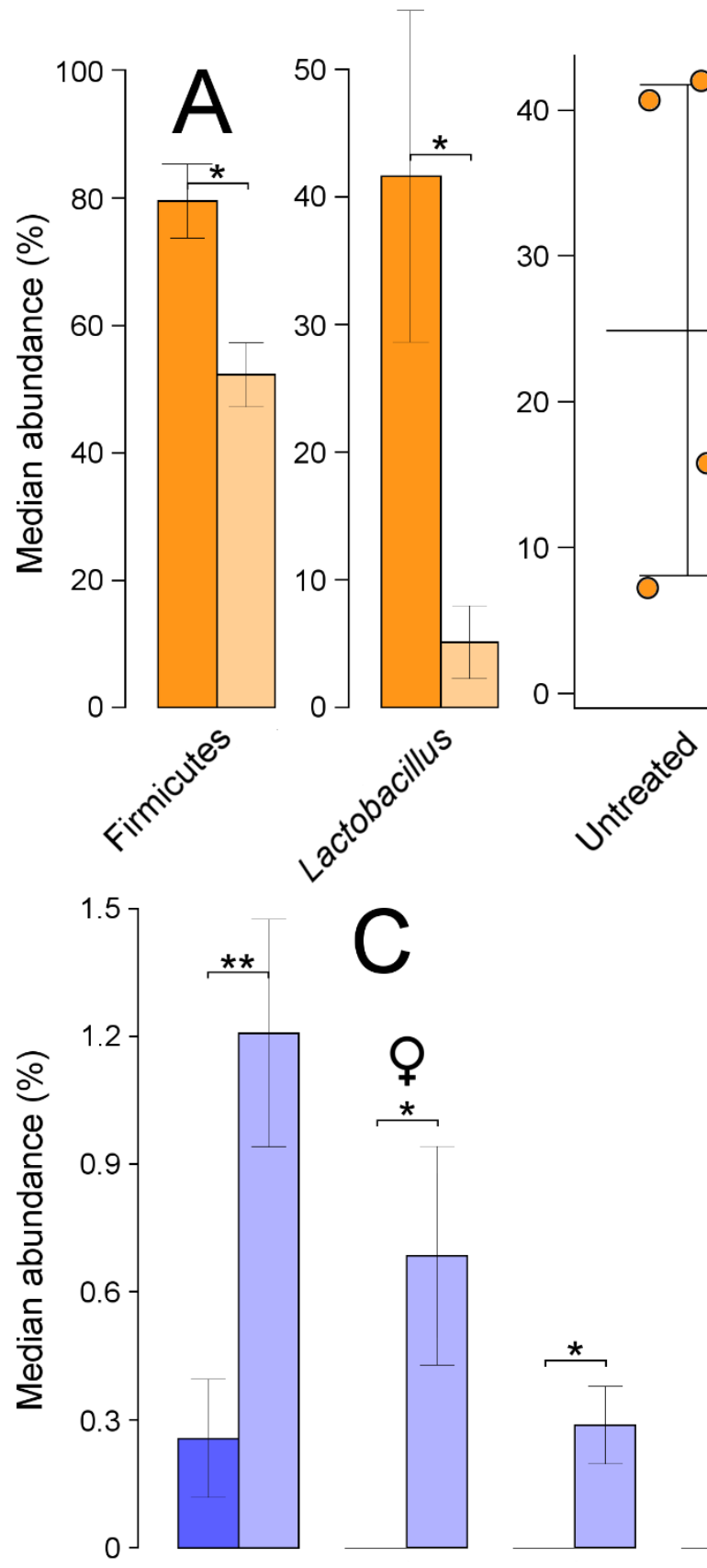

L. agilis
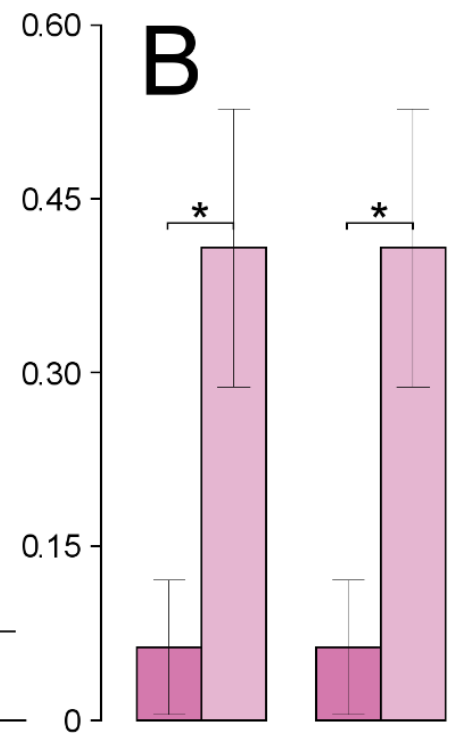

292
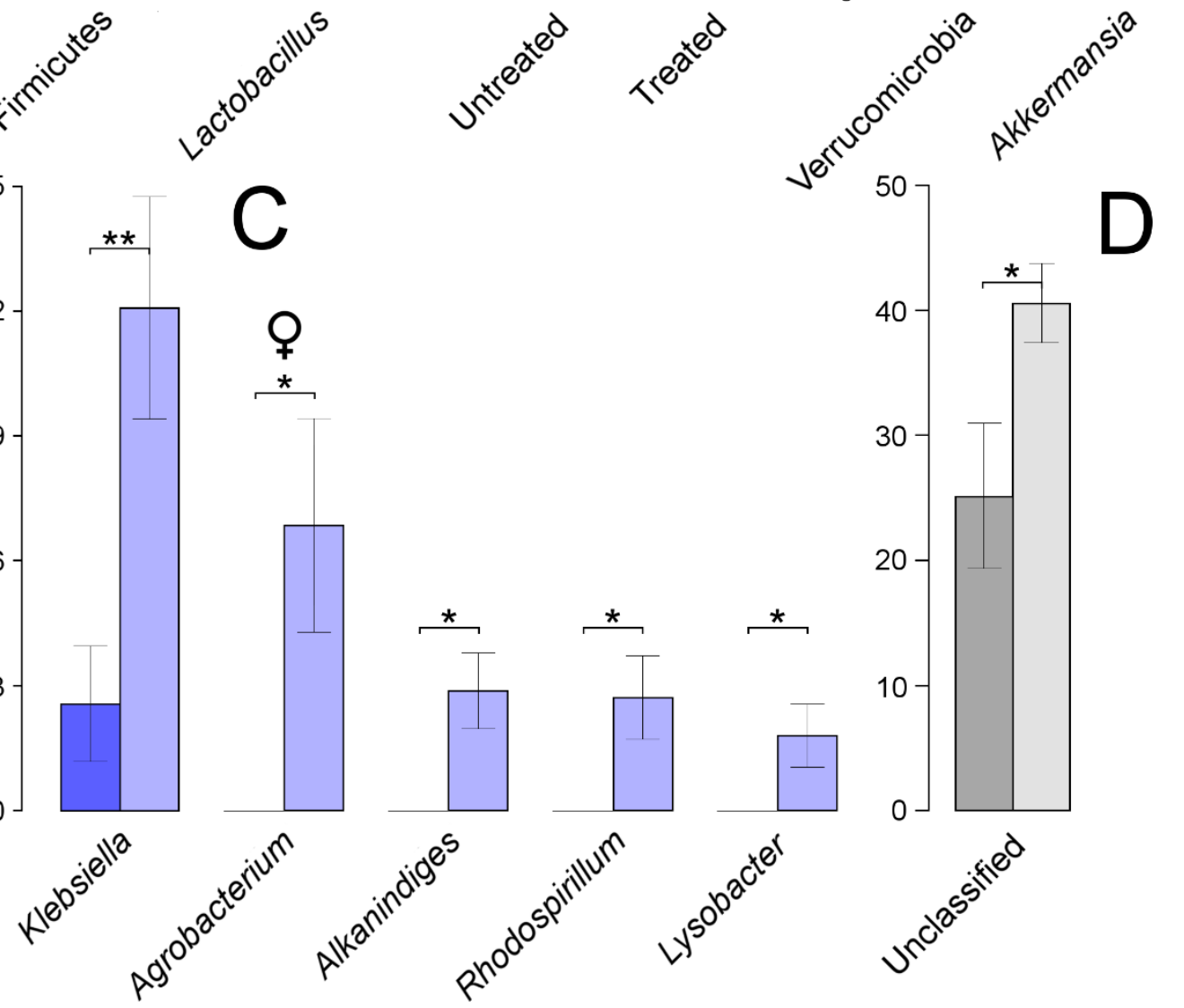

293 Fig. 4. Microbial taxa in the large intestine showing significant shifts. These taxa were grouped in the phyla

294 Firmicutes (A), Verrucomicrobia (B) and Proteobacteria (C). Unclassified taxa is shown in panel D; '*' indicates $295 \mathrm{P} \leq 0.05$, and ' $* *$ ' $\mathrm{P} \leq 0.01$. Light colours indicate treated birds. Sex-dependent significant shifts are indicated with 
296 symbols. To facilitate comparisons across origins, taxa in the same phylum is indicated by same colours in figures 3 , 2974 , and 5.

298 Additionally, the phylum Actinobacteria increased non-significantly from approximately $3 \%$ in 299 untreated to $7 \%$ in treated quails, partly because of relatively low but significant increases in 300 Janibacter ( 0 to $0.3 \%, \mathrm{P}=0.007$ ), and only in females, in Rothia (0 to $0.5 \%, \mathrm{P}=0.044$ ).

301 Additionally, treated females experienced significant increases in the family Bacillaceae ( 0 to $302 \quad 0.7 \%, \mathrm{P}=0.044)$.

303 Faeces

304 Overall, after initial OTU filtering described previously, microbial taxa in quail faeces were 305 classified into 9 phyla, 31 orders, 67 families, 99 genera, and 980 OTUs. Across factors, the 306 main phyla were Firmicutes (approximately 57\% of abundance), Proteobacteria (25\%), and 307 Bacteroidetes (8\%), and the main genera were Lactobacillus (10\%), Faecalibacterium (6\%), and 308 Bacteroides, Clostridium, and Ruminococcus (each 4\%).

309

310

311

312

313

314

315

316

317

318

319

320

321

322

323

324

325

At the phylum level, only treated males showed significant increases in Verrucomicrobia $(\mathrm{P}=0.05)$, which were linked to equally significant increases in the family Verrucomicrobiaceae, and the genus Akkermansia (Fig. 5A). This genus was composed of a single OTU which was assigned to the species, $A$. muciniphila, at $100 \%$ of identity across the amplified region.

Furthermore, the phylum Firmicutes decreased non-significantly when combining results from both sexes, from $59 \%$ in untreated to $55 \%$ in treated quails. Two families from this phylum showed significant increases, Turicibacteraceae $(\mathrm{P}=0.002)$, and Streptococcaceae $(\mathrm{P}=0.001)$, the latter partly caused by a significant increase in the genus Streptococcus ( $\mathrm{P}=0.001)$ (Fig. 5B). Other genera from the same phylum showed significant shifts: significant decreases were found in Eubacterium ( $\mathrm{P}=0.032)$ in treated males, and significant increases were found in Jeotgalicoccus $(\mathrm{P}=0.042)$ in treated females (Fig. 5B). Sphingomonadaceae, a family from the phylum Proteobacteria, was significantly increased in treated quails $(0.33$ to $1.20 \% \mathrm{P}=0.018)$, which resulted from significant increases in the genus Sphingomonas $(\mathrm{P}=0.010)$ (Fig. 5C). Two additional genera were significantly increased in abundances in treated quails, Delftia $(\mathrm{P}=0.010)$ and Brevundimonas $(\mathrm{P}=0.031)$, while Escherichia showed a significant decrease $(\mathrm{P}=0.005)$ (Fig. 5C). Prevotellaceae, a family from the phylum Bacteroidetes, showed significant increases $(\mathrm{P}=0.004)$, caused by an equally significant increase in the genus Prevotella (Fig. 5D). 
326 Additionally, two genera, each from different phylum, varied significantly their abundances,

327 Allobaculum (Tenericutes) $(\mathrm{P}=0.027)$, and Micrococcus (Actinobacteria) $(\mathrm{P}=0.050)$, the latter 328 only in males (Fig. 5E).
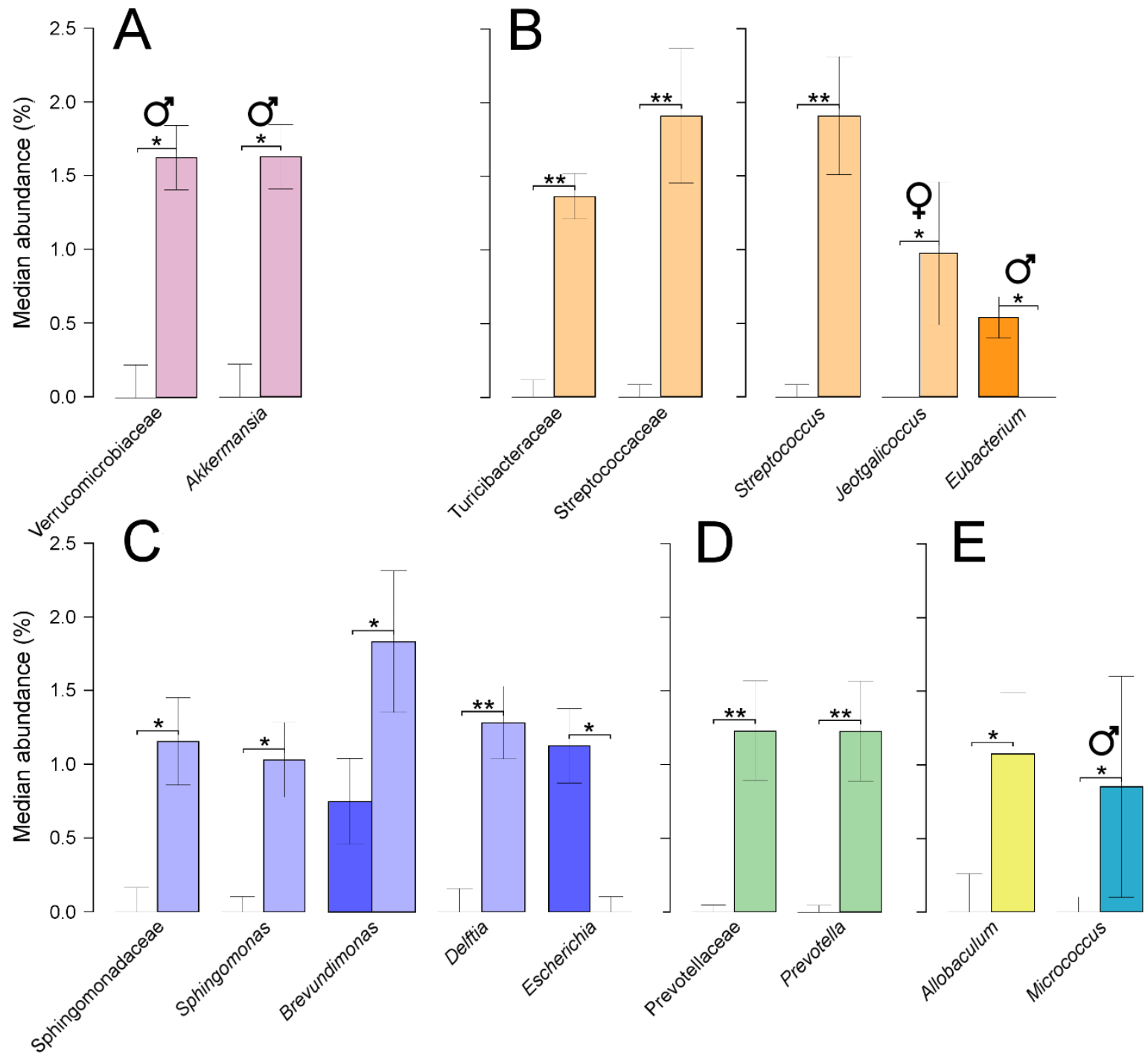

Fig. 5. Faecal microbial taxa showing significant shifts. These taxa were grouped in the phyla Verrucomicrobia (A), Firmicutes (B), Proteobacteria (C), Bacteroidetes (D), and shown together, Tenericutes and Actinobacteria (E). '*' indicates $\mathrm{P} \leq 0.05$, and '**' $\mathrm{P} \leq 0.01$. Light colours indicate treated birds. Sex-dependent significant shifts are indicated with symbols. To facilitate comparisons across origins, taxa in the same phylum is indicated by same colours in figures 3,4 , and 5 .

335 Additionally, several significant changes in abundance occurred in phylotypes that were present 336 in low abundance (below 2\%). There was a significant increase in treated quails in the family Bifidobacteriaceae $(0.2$ to $0.8 \%, \mathrm{P}=0.029)$, linked to equally significant increases in the genus 
338 Bifidobacterium. At similar low abundances, there were significant increases in the family

339 Pasteurellaceae ( 0 to $0.6 \%, \mathrm{P}=0.05$ ) linked to equally significant increases in the genus

340 Haemophilus ( 0 to $0.6 \%, \mathrm{P}=0.03$ ). There were also significant increases in the families

341 Clostridiaceae ( 0.1 to $1.1 \%, \mathrm{P}=0.016)$, Propionibacteriaceae $(0.4$ to $1.2, \mathrm{P}=0.022)$, and

342 'Clostridiales Family XI' ( 0 t $0.6 \%, \mathrm{P}=0.013)$. Increased abundance of the latter two families

343 were linked to an equally significant increase in the genera Propionibacterium and

344 Anaerococcus. Additionally, there were significant increases in the genus Oceanobacillus (0 to

$3450.6 \%, \mathrm{P}=0.013)$ and significant decreases in the genus Eggerthella $(0.25$ to $0 \%, \mathrm{P}=0.013)$.

\section{Discussion}

347 This work explored the short-term impacts of an organophosphate insecticide on the intestinal

348 microbiota of the Japanese quail. Few studies have assessed the impact of insecticides on the

349 GIT (e.g. Joly et al. 2013), but to our knowledge none has been conducted on avian systems in

350 spite of results highlighting the central role that the GIT resident microflora plays in the bird's

351 health (Stanley et al. 2012; van Dongen et al. 2013). Our results revealed that a single oral dose

352 of trichlorfon at low-concentration induced significant shifts in bacterial community composition

353 and diversity across origins. Particularly, our results showed overall increases in Proteobacteria,

354 which have been recently regarded as an indicator of microbial dysbiosis in mammals (Shin et al.

355 2015). In humans, microbiota dysbiosis has been associated with immunological dysregulation

356 (Round \& Mazmanian 2009) and diseases such as diabetes (Qin et al. 2012), irritable bowel

357 syndrome (Chassard et al. 2012), colorectal cancer (Sobhani et al. 2011), and polycystic ovarian

358 syndrome (Tremellen \& Pearce 2012). Although the role of the GIT microbiota is not yet fully

359 understood in humans nor in birds, high microbial diversity is generally considered an indicator

360 of a healthy balance. In contrast, an imbalance generally promotes overgrowth of pathogenic or

361 non-beneficial microbiota, and diseases may occur (Karlsson et al. 2010). This study showed

362 consistency in microbial shifts at high taxonomic level in caecum and large intestine, but not on

363 faeces. However, at lower taxonomic levels, contrasting microbial responses were found between

364 all treatments and origins. 
366 Caecal microbiota showed significantly higher diversity values at an OTU level and highly

367 significant differences in composition compared with the other two origins. These results agree 368 with findings from other studies of Japanese quail (Wilkinson et al. 2016). Significant shifts in 369 microbiota were observed at the phylum level. Firmicutes numbers decreased, while gram370 negative phyla such as Proteobacteria and Bacteroidetes increased in treated quails. Previous 371 studies have shown similar shifts in these three phyla, associated to applications of synthetic 372 pyrethroid insecticides in plant tissue (Zhang et al. 2009).

373 Interestingly, our results showed a significant effect of sex on the microbiota composition in the 374 caecum, which did not occur in the other two origins. Only in females, five genera belonging to 375 Proteobacteria and Bacteroidetes were increased significantly in abundances (i.e. Salmonella, 376 Klebsiella, Erwinia, Serratia, and Bacteroides). It is possible that these and other observed 377 increases in microbiota abundance resulted from their tolerance to the insecticide. Some bacteria 378 have the catabolic ability to dissolve insecticides and use them as a carbon source, an ability 379 termed as biodegradation (Akbar et al. 2014). For instance, the latter study showed that 380 Proteobacteria was the only dominant bacterial group selected by enrichment culturing using 381 chlorpyrifos (and organophosphate pesticide) as the carbon source. Other studies have found that 382 Klebsiella and Serratia are efficient organophosphate biodegraders (Cycoń et al. 2009; Pino \& 383 Peñuela 2011; Sasikala et al. 2012). Furthermore, Joly et al. (2013) found significant increases in Bacteroidetes in both the intestine of rats and in a human intestine simulator, after the continuous application of low doses of an organophosphate insecticide. Burkholder et al. (2008) showed that acute stressors resulted in shifts in GIT microbiota and increases in Salmonella abundances. Thus, it is likely that some of the aforementioned taxa increased as they were not adversely affected and hence had a relative advantage compared to other bacteria, as a consequence of their biodegradation ability. Additionally, three genera from the Lachnospiraceae family decreased, but Blautia and Eubacterium did so only in females. Eubacterium produce butyrate, which is considered a gut health promoter through cell growth and colonic cell turnover (Gong et al. 2002). Another study reported increases in abundance of a number of caecal bacteria, including Blautia, associated to an improvement of $10 \%$ in feed conversion ratio in broilers (Li et al. 2016). In general, the Lachnospiraceae family has been associated with improved growth performance in chickens (i.e. lower food conversion ratio) (Stanley et al. 2012). Therefore, the 396 aforementioned decreases are potentially associated with negative effects on the health of quails. 
397 Other studies have indicated that there are sex-dependent changes in environmental conditions

398 (e.g. pH and oxygen gradients, bile acid levels) throughout the GIT of female quails (Flint et al.

399 2012; Islam et al. 2011) and this may provide a clue as to why there are sex related differences in

400 the microbiota within the caecum. Our results indicate that in the caecum of treated females, a

401 number of bacteria, including all Enterobacteriaceae members, formed a microbial consortium

402 which negatively correlated with the abundance of Firmicutes. Although we cannot predict the

403 health risks that these microbiota shifts may invoke, a number of studies have shown the

404 detrimental impact that some of these bacterial groups have. Most of the genera that increased in

405 abundance belonged to Enterobacteriaceae. Based on findings from deceased birds, it has been

406 suggested that bacteria from this family predispose birds to diseases (Glünder 2002). Particularly

407 in the Salmonella genus, several reports in Europe and America have associated the death of

408 different wild bird species due to Salmonellosis (Craven et al. 2000). Other studies associated

409 very high abundances of Bacteroidetes in patients suffering irritable bowel syndrome ( $\mathrm{Ng}$ et al.

410 2013). Moreover, increases in Bacteroides growth in the intestines of two different animals were

411 associated with decreases in probiotics such as lactobacilli and bifidobacteria (Joly et al. 2013).

412 Results from these studies suggest that the shifts we observed in our study, particularly in the

413 case of female quails, could predispose birds to the development of diseases. However, further

414 research is necessary to clarify the mechanisms and the consequences of these microbiota shifts.

\section{Large intestine}

416 Significant Treatment $\times$ Origin interactions in microbiota composition were found in this study.

417 Significant changes in microbiota composition were found between the large intestine and faeces

418 in treated quails while no significant changes were found in the untreated quails. There were

419 large reductions of Lactobacillus (phylum Firmicutes) in the large intestine of treated birds. This

420 genus is generally present in normal mucosal microbiota in most animals (Kapczynski et al.

421 2000), and numerous studies have investigated their probiotic effects in avian systems. Early

422 research showed that high abundance of this genus can inhibit Escherichia coli growth in

423 chicken crop (Fuller 1977). More recently, Timmerman et al. (2006) showed that administering

424 probiotic Lactobacillus species to broilers promoted their growth and reduced mortality. In our

425 study, the most affected species of Lactobacillus was L. agilis. Lan et al. (2004) showed that this

426 species, along with other Lactobacillus strains, restored the balance and maintained the natural 
427 stability of bacterial microbiota after heat stress-induced changes. In another study, probiotic

428 supplements composed of L. agilis and L. salivarius enhanced lactobacilli and bifidobacteria 429 abundance, and inhibited Salmonella growth in a simulated chicken caecum (Meimandipour et 430 al. 2010). However, there are number of studies questioning the beneficial effects of 431 Lactobacillus probiotics in birds (e.g. Goodling et al. 1987) and their effect on the bird health 432 cannot be taken as independent from the rest of the microbial community structure as it is often 433 done in the literature. In this study, differences observed in Lactobacillus abundance between 434 treated and untreated quails could point to the lack of adaptive responses of this biota to the new 435 chemical environment of the large intestine. Additionally, it is possible that the reductions 436 observed in Lactobacillus in treated quails could cause detrimental consequences for their health.

437 Similarly to the results found in caecum, the large intestine of treated quails had increases in the 438 abundance of Proteobacteria, which occurred as a result of significant increases in five genera (i.e. Alkanindiges, Lysobacter, Agrobacterium, Rhodospirillum, and Klebsiella). Significant increases in the latter genus were also found in the caecum. Furthermore, treated quails showed increased abundances of Verrucomicrobia, a poorly characterized phylum (Hou et al. 2008), both in the large intestine and in faeces. Increases in this phylum were attributed to a sole species, Akkermansia muciniphila. This bacteria degrades intestinal mucin to obtain carbon and nitrogen (Van Passel et al. 2011). In mice, it was suggested that intestinal bacteria producing excessive mucin degradation could contribute to inflammatory bowel diseases, since of luminal antigens to the intestinal immune system was facilitated (Ganesh et al. 2013). Increases in A. muciniphila abundance have been negatively correlated with body weight in humans and rodents (Everard et al. 2013). Moreover, studies have shown that overweighted people undergoing a fasting program showed increased abundance of Akkermansia in their gut microbiota (Remely et al. 2015). During our study, insecticide-treated quails were fasting (by reducing feed intake), most likely as a consequence of trichlorfon ingestion. It is thus hypothesised that fasting in insecticide-treated birds might have contributed to higher abundances of $A$. muciniphila, in comparison with untreated birds which were feeding normally. Lastly, our results showed further insecticide impact through an increase of unclassified bacteria to relative abundances above $40 \%$ in treated quails. Although the identity of the latter group is unknown, it is possible that it could be partially represented by phyla which showed positive responses to insecticide (e.g. 
458 Faeces

459 Several microbiota taxa were significantly affected by trichlorfon in faeces, however, most of 460 these changes occurred at much lower abundance levels than in the other two origins. Compared 461 to the other origins, faecal microbiota showed consistent responses in taxa associated to the 462 phyla Verrucomicrobia and Proteobacteria as shown in this study. However, increases in taxa in 463 the Firmicutes phylum occurred concurrently with decreases in the same phylum in the other 464 origins, showing an inconsistency in the faecal microbiota responses. It is not unusual to observe 465 inconsistencies such as a lack of a unidirectional, dose-response correlation in microbial 466 toxicology tests (Petersen et al. 2004; Widenfalk et al. 2008). Furthermore, it is well accepted 467 that avian faecal microbiota oscillates based on the regular emptying of different GIT sections 468 (Sekelja et al. 2012). In a recent study, source-sink predictions of the seeding dynamics across 469 different GIT sections of Japanese quail showed that most of the faecal microbiota composition 470 had a multi-source predicted origin, with major origins contributing to it being caecum, and large 471 intestine (Wilkinson et al. 2016). Thus, it is possible that the results observed in the faecal 472 samples of treated quails originated from a combined reaction of different origins in the GIT to 473 the insecticide.

\section{Conclusions}

475 A single sub-lethal exposure to an organophosphate insecticide, at concentrations similar to 476 levels likely to be ingested following insecticide spraying in an orchard, caused significant 477 changes in avian gut microbiota within 24 hours. The effect size of this change, and the shifts in 478 microbial groupings, are consistent with microbiotas that previous studies have shown may 479 predispose birds to diseases. The changes differ between parts of the GIT, and interestingly also 480 differ between sexes, particularly in the caecum.

481 The study revealed that increases in abundance of certain microbial taxa occurred as a result of 482 direct or indirect positive interactions with trichlorfon administration, some possibly as a result 483 of their biodegradation ability. On the other hand, reductions observed in other groups likely 484 arose from their susceptibility to the insecticide, which may have produced antagonism and/or 485 competition with overgrowing biodegradative and/or insecticide-tolerant taxa. 
486 This study raise several questions that should be addressed to understand the interactions

487 between GIT microbiota and avian hosts, the effects of pesticides on these interactions, and the 488 overall consequences for the bird's health. Further research is necessary to unravel the 489 mechanisms driving the interactions, and to understand how these are potentially associated with 490 damage, and/or the development of diseases in the GIT. Additionally, further study of short term 491 physiological responses and longer term health impacts are warranted based on the study results.

492 Considering that we carried out this study in a laboratory under defined and stable conditions, 493 our results can only partially mimic what is likely to occur under field conditions after 494 insecticides are sprayed. Nevertheless, our results suggest that changes in microbiota associated 495 to even small doses of insecticide could impose health risks on birds, particularly in females. The 496 implications of the significant response to a low dose of an organophosphate insecticide are that

497 498 499

500

501

502 503

504 505 506 acute and chronic health impacts are likely to occur in avian populations if similar GIT responses occur under field conditions. These results are relevant for the conservation of avian communities in agricultural areas where organophosphates are regularly sprayed.

\section{Acknowledgements}

We are grateful to Clive and Erika Wiley (owners of Banyard Game Farms), who provided the quails used in this study. We would like to thank Honglei Chen for operating the Illumina MiSeq instrument. All data analyses were performed on the Isaac Newton High Performance Computing System at Central Queensland University. We acknowledge the support received from Jason Bell in all aspects of High Performance Computing as well as the additional support received from Giselle Weegenaar, Ingrid Christiansen and Judy Couper.

\section{References}

Akbar S, Sultan S, and Kertesz M. 2014. Bacterial community analysis in chlorpyrifos enrichment cultures via DGGE and use of bacterial consortium for CP biodegradation. World Journal of Microbiology and Biotechnology 30:2755-2766.

Altschul SF, Madden TL, Schaffer AA, Zhang J, Zhang Z, Miller W, Lipman DJ. 1997. Gapped BLAST and PSI-BLAST: a new generation of protein database search programs. Nucleic Acids Research 25:3389-3402.Anderson M, and Braak CT. 2003. Permutation tests for 
514

515

516

517

518

519

520

521

522

523

524

525

526

527

528

529

530

531

532

533

534

535

536

537

538

539

540

541

542

543

multi-factorial analysis of variance. Journal of statistical computation and simulation $73: 85-113$.

Anderson MJ. 2005. Permutational multivariate analysis of variance. Auckland: University of Auckland. Available at http://img2.timg.co.il/forums/1_124959686.pdf

Ashelford KE, Chuzhanova NA, Fry JC, Jones AJ, and Weightman AJ. 2005. At least 1 in 20 16S rRNA sequence records currently held in public repositories is estimated to contain substantial anomalies. Applied and Environmental Microbiology 71:7724-7736.

Bondarenko S, Gan J, Haver DL, and Kabashima JN. 2004. Persistence of selected organophosphate and carbamate insecticides in waters from a coastal watershed. Environmental Toxicology and Chemistry 23:2649-2654.

Burkholder K, Thompson K, Einstein M, Applegate T, and Patterson J. 2008. Influence of stressors on normal intestinal microbiota, intestinal morphology, and susceptibility to Salmonella enteritidis colonization in broilers. Poultry Science 87:1734-1741.

Caporaso JG, Kuczynski J, Stombaugh J, Bittinger K, Bushman FD, Costello EK, Fierer N, Pena AG, Goodrich JK, and Gordon JI. 2010. QIIME allows analysis of high-throughput community sequencing data. Nature Methods 7:335-336.

Chassard C, Dapoigny M, Scott K, Crouzet L, Del'Homme C, Marquet P, Martin J, Pickering G, Ardid D, and Eschalier A. 2012. Functional dysbiosis within the gut microbiota of patients with constipated-irritable bowel syndrome. Alimentary Pharmacology \& Therapeutics $35: 828-838$.

Craven S, Stern N, Line E, Bailey J, Cox N, and Fedorka-Cray P. 2000. Determination of the incidence of Salmonella spp., Campylobacter jejuni, and Clostridium perfringens in wild birds near broiler chicken houses by sampling intestinal droppings. Avian Diseases 44:715720.

Cycoń M, Wójcik M, and Piotrowska-Seget Z. 2009. Biodegradation of the organophosphorus insecticide diazinon by Serratia sp. and Pseudomonas sp. and their use in bioremediation of contaminated soil. Chemosphere 76:494-501.

de Oliveira GH, Moreira V, and Goes SPR. 2002. Organophosphate induced delayed neuropathy in genetically dissimilar chickens: studies with tri-ortho-cresyl phosphate (TOCP) and trichlorfon. Toxicology Letters 136:143-150. 
544 Dumonceaux TJ, Hill JE, Hemmingsen SM, and Van Kessel AG. 2006. Characterization of 545 intestinal microbiota and response to dietary virginiamycin supplementation in the broiler $546 \quad$ chicken. Applied and Environmental Microbiology 72:2815-2823.

547 Edgar RC. 2010. Search and clustering orders of magnitude faster than BLAST. Bioinformatics $548 \quad 26: 2460-2461$.

549 Everard A, Belzer C, Geurts L, Ouwerkerk JP, Druart C, Bindels LB, Guiot Y, Derrien M, 550 Muccioli GG, and Delzenne NM. 2013. Cross-talk between Akkermansia muciniphila and 551 552 intestinal epithelium controls diet-induced obesity. Proceedings of the National Academy of Sciences 110:9066-9071.

553 554 555 556 557 558 559

Fadrosh DW, Ma B, Gajer P, Sengamalay N, Ott S, Brotman RM, and Ravel J. 2014. An improved dual-indexing approach for multiplexed 16S rRNA gene sequencing on the Illumina MiSeq platform. Microbiome 2:1-7.

Fleischli MA, Franson J, Thomas N, Finley D, and Riley Jr W. 2004. Avian mortality events in the United States caused by anticholinesterase pesticides: a retrospective summary of National Wildlife Health Center records from 1980 to 2000. Archives of Environmental Contamination and Toxicology 46:542-550.

Flint HJ, Scott KP, Louis P, and Duncan SH. 2012. The role of the gut microbiota in nutrition and health. Nature Reviews Gastroenterology and Hepatology 9:577-589.

Foudoulakis M, Balaskas C, Csato A, Szentes C, and Arapis G. 2013. Japanese quail acute exposure to methamidophos: Experimental design, lethal, sub-lethal effects and cholinesterase biochemical and histochemical expression. Science of the Total Environment 450:334-347.

Frank R, Mineau P, Braun H, Barker I, Kennedy S, and Trudeau S. 1991. Deaths of Canada geese following spraying of turf with diazinon. Bulletin of Environmental Contamination and Toxicology 46:852-858.

Fuller R. 1977. The importance of lactobacilli in maintaining normal microbial balance in the crop. British Poultry Science 18:85-94.

Ganesh BP, Klopfleisch R, Loh G, and Blaut M. 2013. Commensal Akkermansia muciniphila exacerbates gut inflammation in Salmonella typhimurium-infected gnotobiotic mice. PloS one 8:e74963. 
574 Glünder G. 2002. Influence of diet on the occurrence of some bacteria in the intestinal flora of $575 \quad$ wild and pet birds. DTW Deutsche tierarztliche Wochenschrift 109:266-270.

576 Golden NH, and Rattner BA. 2003. Ranking terrestrial vertebrate species for utility in

577

578

579

580

581

582

583

584

585

586

587

588

589

590

591

592

593

594

595

596

597

598

599

600

601

602 biomonitoring and vulnerability to environmental contaminants. In: Reviews of Environmental Contamination and Toxicology. New York: Springer, 67-136.

Goldstein M, Lacher TE, Woodbridge B, Bechard MJ, Canavelli SB, Zaccagnini ME, Cobb GP, Scollon EJ, Tribolet R, and Hopper MJ. 1999. Monocrotophos-Induced Mass Mortality of Swainson's Hawks in Argentina, 1995-96. Ecotoxicology 8:201-214. 10.1023/A:1026496331396

Goldstein MI, Woodbridge B, Zaccagnini ME, and Canavelli SB. 1996. An assessment of mortality of Swainson's Hawks on wintering grounds in Argentina. Journal of Raptor Research 30:106-107.

Golian A, and Maurice D. 1992. Dietary poultry fat and gastrointestinal transit time of feed and fat utilization in broiler chickens. Poultry Science 71:1357-1363.

Gong J, Forster RJ, Yu H, Chambers JR, Sabour PM, Wheatcroft R, and Chen S. 2002. Diversity and phylogenetic analysis of bacteria in the mucosa of chicken ceca and comparison with bacteria in the cecal lumen. FEMS Microbiology Letters 208:1-7.

Goodling A, Cerniglia G, and Hebert J. 1987. Production performance of white leghorn layers fed Lactobacillus fermentation products. Poultry Science 66:480-486.

Hill EF. 1982. Anticholinesterase poisoning of birds: Field monitoring and diagnosis of acute poisoning. Environmental Toxicology and Chemistry 1:27-38.

Hill EF, Heath RG, Spawn JW, and Williams JD. 1975. Lethal dietary toxicities of environmental pollutants to birds. Special Scientific Report 191. US Fish and Wildlife Service.

Hou S, Makarova KS, Saw J, Senin P, Ly BV, Zhou Z, Ren Y, Wang J, Galperin MY, and Omelchenko MV. 2008. Complete genome sequence of the extremely acidophilic methanotroph isolate V4, Methylacidiphilum infernorum, a representative of the bacterial phylum Verrucomicrobia. Biology Direct 3:26. Iko WM, Archuleta AS, and Knopf FL. 2003. Plasma cholinesterase levels of Mountain Plovers (Charadrius montanus) wintering in central California, USA. Environmental Toxicology and Chemistry 22:119-125. 
603 Islam KS, Fukiya S, Hagio M, Fujii N, Ishizuka S, Ooka T, Ogura Y, Hayashi T, and Yokota A. 604 2011. Bile acid is a host factor that regulates the composition of the cecal microbiota in 605 rats. Gastroenterology 141:1773-1781.

606 Joly C, Gay-Quéheillard J, Léké A, Chardon K, Delanaud S, Bach V, and Khorsi-Cauet H. 2013. 607 Impact of chronic exposure to low doses of chlorpyrifos on the intestinal microbiota in the 608 Simulator of the Human Intestinal Microbial Ecosystem (SHIME®) and in the rat. 609 Environmental Science and Pollution Research 20:2726-2734.

610 Kamada N, Seo S-U, Chen GY, and Núñez G. 2013. Role of the gut microbiota in immunity and 611 inflammatory disease. Nature Reviews Immunology 13:321-335.

612 Kapczynski DR, Meinersmann RJ, and Lee MD. 2000. Adherence of Lactobacillus to intestinal 613 407 cells in culture correlates with fibronectin binding. Current Microbiology 41:136-141.

Karlsson C, Ahrné S, Molin G, Berggren A, Palmquist I, Fredrikson GN, and Jeppsson B. 2010.

615

616 Probiotic therapy to men with incipient arteriosclerosis initiates increased bacterial

617 diversity in colon: a randomized controlled trial. Atherosclerosis 208:228-233.

618

619

620

621

622

623

624

625

626

627

628

629

Meimandipour A, Shuhaimi M, Soleimani A, Azhar K, Hair-Bejo M, Kabeir B, Javanmard A, 630 Anas OM, and Yazid A. 2010. Selected microbial groups and short-chain fatty acids profile

631

632 in a simulated chicken cecum supplemented with two strains of Lactobacillus. Poultry Science 89:470-476. 
633 Myers SP. 2004. The causes of intestinal dysbiosis: a review. Alternative Medicine Review 9:180634197.

635 Ng SC, Lam EF, Lam TT, Chan Y, Law W, Tse PC, Kamm MA, Sung JJ, Chan FK, and Wu JC. 636 2013. Effect of probiotic bacteria on the intestinal microbiota in irritable bowel syndrome. Journal of Gastroenterology and Hepatology 28:1624-1631.

Paulson JN, Stine OC, Bravo HC, and Pop M. 2013. Differential abundance analysis for microbial 639 marker-gene surveys. Nature Methods 10:1200-1202.

Petersen DG, Dahllof I, and Nielsen LP. 2004. Effects of zinc pyrithione and copper pyrithione on 641 microbial community function and structure in sediments. Environmental Toxicology and Chemistry 23:921-928.

Pino N, and Peñuela G. 2011. Simultaneous degradation of the pesticides methyl parathion and 644 chlorpyrifos by an isolated bacterial consortium from a contaminated site. International Biodeterioration \& Biodegradation 65:827-831.

Qin J, Li Y, Cai Z, Li S, Zhu J, Zhang F, Liang S, Zhang W, Guan Y, and Shen D. 2012. A 647

648 metagenome-wide association study of gut microbiota in type 2 diabetes. Nature 490:5560.

Remely M, Hippe B, Geretschlaeger I, Stegmayer S, Hoefinger I, and Haslberger A. 2015. 650 Increased gut microbiota diversity and abundance of Faecalibacterium prausnitzii and Akkermansia after fasting: a pilot study. Wiener klinische Wochenschrift 127:394-398.

Round JL, and Mazmanian SK. 2009. The gut microbiota shapes intestinal immune responses 653 during health and disease. Nature Reviews Immunology 9:313-323.

Sasikala C, Jiwal S, Rout P, and Ramya M. 2012. Biodegradation of chlorpyrifos by bacterial 655 consortium isolated from agriculture soil. World Journal of Microbiology and Biotechnology 28:1301-1308.

658

Sekelja M, Rud I, Knutsen S, Denstadli V, Westereng B, Naes T, and Rudi K. 2012. Abrupt temporal fluctuations in the chicken fecal microbiota are explained by its gastrointestinal origin. Applied and Environmental Microbiology 78:2941-2948.

Shin N-R, Whon TW, and Bae J-W. 2015. Proteobacteria: microbial signature of dysbiosis in gut microbiota. Trends in Biotechnology 33:496-503.

Slott V, and Ecobichon D. 1984. An acute and subacute neurotoxicity assessment of trichlorfon. 663 Canadian Journal of Physiology and Pharmacology 62:513-518. 
664 Smith PN, Cobb GP, Godard-Codding C, Hoff D, McMurry ST, Rainwater TR, and Reynolds KD. 665 2007. Contaminant exposure in terrestrial vertebrates. Environmental Pollution 150:41-64. 666 Sobhani I, Tap J, Roudot-Thoraval F, Roperch JP, Letulle S, Langella P, Corthier G, Tran Van 667 Nhieu J, and Furet JP. 2011. Microbial dysbiosis in colorectal cancer (CRC) patients. PloS 668 one 6:e16393.

669 Stanley D, Geier M, Hughes R, and Moore R. 2012. The role of gastrointestinal tract microbiota 670 in chicken productivity. Proceedings of the Australian Poultry Science Symposium. $671 \quad 24: 262-265$.

672 Stanley D, Geier MS, Hughes RJ, Denman SE, and Moore RJ. 2013. Highly variable microbiota 673 development in the chicken gastrointestinal tract. PloS One 8:e84290.

674 Stanley D, Hughes RJ, and Moore RJ. 2014. Microbiota of the chicken gastrointestinal tract: 675 influence on health, productivity and disease. Applied Microbiology and Biotechnology $67698: 4301-4310$.

677 Su H, McKelvey J, Rollins D, Zhang M, Brightsmith DJ, Derr J, and Zhang S. 2014. Cultivable 678 nacterial microbiota of northern bobwhite (Colinus virginianus): a new reservoir of 679 antimicrobial resistance? PloS One 6:e99826.

680 Sullivan JP, and Wisk JD. 2013. Using the terrestrial residue exposure (T-REX) model to assess 681 threatened and endangered bird exposure to and risk from pesticides. Integrated 682 Environmental Assessment and Management 9:480-495.

683 Timmerman H, Veldman A, Van den Elsen E, Rombouts F, and Beynen A. 2006. Mortality and 684 growth performance of broilers given drinking water supplemented with chicken-specific 685 probiotics. Poultry Science 85:1383-1388.

686 Tremellen K, and Pearce K. 2012. Dysbiosis of Gut Microbiota (DOGMA)-a novel theory for the 687 development of Polycystic Ovarian Syndrome. Medical Hypotheses 79:104-112.

688 Umesaki Y, Setoyama H, Matsumoto S, Imaoka A, and Itoh K. 1999. Differential roles of 689 segmented filamentous bacteria and clostridia in development of the intestinal immune $690 \quad$ system. Infection and Immunity 67:3504-3511.

691 USEPA. 1993. Wildlife exposure factors handbook. Washington DC: US Environmental 692 Protection Agency. 
693 van Dongen WF, White J, Brandl HB, Moodley Y, Merkling T, Leclaire S, Blanchard P, Danchin 694 É, Hatch SA, and Wagner RH. 2013. Age-related differences in the cloacal microbiota of 695 a wild bird species. BMC Ecology 13:11.

696 Van Passel M, Kant R, Zoetendal EG, Plugge CM, Derrien M, Malfatti SA, Chain P, Woyke T, 697 Palva A, and de Vos WM. 2011. The genome of Akkermansia muciniphila, a dedicated 698 intestinal mucin degrader, and its use in exploring intestinal metagenomes. PloS One $699 \quad 6: \mathrm{e} 16876$.

700 Waite DW, and Taylor MW. 2014. Characterizing the avian gut microbiota: membership, driving 701 influences, and potential function. Frontiers in Microbiology 5:223.

Widenfalk A, Bertilsson S, Sundh I, and Goedkoop W. 2008. Effects of pesticides on community composition and activity of sediment microbes - responses at various levels of microbial community organization. Environmental Pollution 152:576-584.

Wilkinson N, Hughes RJ, Aspden WJ, Chapman J, Moore RJ, and Stanley D. 2016. The gastrointestinal tract microbiota of the Japanese quail, Coturnix japonica. Applied Microbiology and Biotechnology DOI:10.1007/s00253-015-7280-z.

Woodard A, and Abplanalp H. 1971. Longevity and reproduction in Japanese quail maintained under stimulatory lighting. Poultry Science 50:688-692.

Zamy C, Mazellier P, and Legube B. 2004. Phototransformation of selected organophosphorus pesticides in dilute aqueous solutions. Water Research 38:2305-2314.

Zhang B, Bai Z, Hoefel D, Tang L, Wang X, Li B, Li Z, and Zhuang G. 2009. The impacts of cypermethrin pesticide application on the non-target microbial community of the pepper plant phyllosphere. Science of the Total Environment 407:1915-1922. 